\title{
recillunds
}

Revista Cientifica Mundo de la Investigación y el Conocimiento

\author{
Carlos Pedro Marcillo Carvajal a; Anita María Murillo Zavala ${ }^{\text {b; }}$ María Isabel \\ Peñaherrera Ortiz ${ }^{\mathrm{c}}$; Irma Gisella Parrales Pincay ${ }^{\mathrm{d}}$
}

Síndrome diarreico infeccioso causado por Salmonella spp

Infectious diarrheal syndrome caused by Salmonella spp

Revista Científica Mundo de la Investigación y el Conocimiento. Vol. 3 núm.3, septiembre, ISSN: 2588-073X, 2019, pp. 493-508

DOI: $10.26820 /$ recimundo/3.(3).septiembre.2019.493-508

URL: http://recimundo.com/index.php/es/article/view/533

Código UNESCO: 3205 Medicina Interna

Tipo de Investigación: Artículo de Revisión

Editorial Saberes del Conocimiento

Recibido: 15/05/2019

Aceptado: 23/06/2019

Publicado: 30/09/2019

Correspondencia: carlos.marcillo@unesum.edu.ec

a. Licenciado en Laboratorio Clínico; Universidad Estatal del Sur de Manabí, Ecuador; carlos.marcillo@unesum.edu.ec

b. Magister en Gerencia y Administración de Salud; Licenciado en Laboratorio Clínico; Universidad Estatal del Sur de Manabí, Ecuador; anita.murillo@unesum.edu.ec

c. Licenciada en Laboratorio Clínico; Universidad Estatal del Sur de Manabí, Ecuador; irma.parrales@unesum.edu.ec

d. Magister en Gerencia Educativa; Licenciada en Ciencias de la Educación General Básica; Universidad Estatal del Sur de Manabí, Ecuador; mipo51991@hotmail.com 


\section{Síndrome diarreico infeccioso causado por Salmonella spp}

Vol. 3, núm. 3., (2019)

Carlos Pedro Marcillo Carvajal; Anita María Murillo Zavala; María Isabel Peñaherrera Ortiz; Irma Gisella Parrales Pincay

\section{RESUMEN}

La salmonelosis, causada por la bacteria Salmonella, es una de las enfermedades de transmisión alimentaria más comunes y ampliamente extendidas. Se estima que afecta anualmente a decenas de millones de personas de todo el mundo y provoca más de cien mil defunciones. Entre las recomendaciones para evitar su propagación y contagio están, realizar lavado de manos tras cambiar pañales, ir al baño, tocar animales o sacar la basura, quedarse en casa si usted está enfermo, no criar animales tipo reptil, prestar atención a los alimentos que se ingieren, no beber leche sin pasteurizar o comer alimentos hechos en ella, entre otras. Esta investigación se enfoca en la búsqueda y revisión de literatura científico académica que, fundamentalmente, pudo accederse mediante el aprovechamiento de diversas bases de datos. Con los resultados obtenidos, entre otros aspectos, principalmente se logró el análisis de importancia de la prevención de riesgos sobre la propagación de la enfermedad y sus posibles tratamientos. Se concluye destacando que ésta complicación sigue padeciéndose en diferentes partes del mundo, especialmente en países en vías de desarrollo. Así mismo, la transmisión y desarrollo de infecciones relacionadas a Salmonella son de especial cuidado. El uso continuo de antibióticos ha generado la aparición de cepas resistentes en varios lugares en el mundo, tal y como ha ocurrido con otras bacterias, lo que genera una necesidad creciente por un mayor apego a los protocolos de manejo y a su vez una correcta educación en el uso de los antibacterianos para los pacientes a quienes se les suministra estas terapias.

Palabras Claves: Bactéria; Contagio; Pasteurizar; Cepas; Protocolos. 


\title{
Síndrome diarreico infeccioso causado por Salmonella spp
}

Vol. 3, núm. 3., (2019)

Carlos Pedro Marcillo Carvajal; Anita María Murillo Zavala; María Isabel Peñaherrera Ortiz; Irma Gisella Parrales Pincay

\begin{abstract}
Salmonellosis, caused by Salmonella bacteria, is one of the most common and widely spread foodborne diseases. It is estimated that it affects tens of millions of people around the world annually and causes more than one hundred thousand deaths. Among the recommendations to prevent its spread and contagion are, perform handwashing after changing diapers, going to the bathroom, touching animals or taking out the trash, staying home if you are sick, not raising reptile-like animals, paying attention to the foods that they are ingested, do not drink unpasteurized milk or eat food made in it, among others. This research focuses on the search and review of academic scientific literature that, fundamentally, could be accessed through the use of various databases. With the results obtained, among other aspects, the analysis of the importance of risk prevention on the spread of the disease and its possible treatments was mainly achieved. It is concluded by highlighting that this complication continues to suffer in different parts of the world, especially in developing countries. Likewise, the transmission and development of Salmonella-related infections are of special care. The continuous use of antibiotics has generated the emergence of resistant strains in several places in the world, as has happened with other bacteria, which creates a growing need for greater adherence to management protocols and in turn a proper education in the use of antibacterials for patients who are given these therapies.
\end{abstract}

Key words: Bacteria; Contagion; Pasteurize; Strains; Protocols. 


\section{Síndrome diarreico infeccioso causado por Salmonella spp}

Vol. 3, núm. 3., (2019)

Carlos Pedro Marcillo Carvajal; Anita María Murillo Zavala; María Isabel Peñaherrera Ortiz; Irma Gisella Parrales Pincay

\section{Introducción.}

Las enfermedades gastrointestinales son una de las primeras causas de consulta médica y también una de las primeras causas de muerte en el mundo. Es así, que son consideradas por (Hernández C, 2011) “un problema de salud pública en el nivel mundial, que afecta a personas de cualquier edad y condición social, aunque los grupos más vulnerables son los niños y los ancianos".

La Enterocolitis por salmonela es una infección bacteriana en el revestimiento del intestino delgado causada por la bacteria salmonela. Es un tipo de intoxicación por alimentos. La infección por salmonela es uno de los tipos más comunes de intoxicación alimentaria. Esto ocurre cuando usted consume alimentos o agua que contienen la bacteria salmonela. Los microorganismos de la salmonela pueden penetrar en el alimento que usted come de varias maneras.

Se puede resaltar, que estudios realizados mundialmente han demostrado que las infecciones gastrointestinales son una de las causas más importantes de morbimortalidad entre los lactantes y niños. Se ha estimado que en Asia, África y Latinoamérica la probabilidad de que un niño muera antes de los 5 años puede llegar a 50\%, aunque esto depende de factores socioeconómicos y nutricionales. Las enfermedades gastrointestinales infecciosas son causadas por bacterias (principalmente Escherichia coli, Salmonella y Shigella), parásitos (Giardia lamblia y amibas), y virus (Rotavirus y virus Norwalk) al consumir alimentos y agua contaminados con materia fecal. 


\section{Síndrome diarreico infeccioso causado por Salmonella spp}

Vol. 3, núm. 3., (2019)

Carlos Pedro Marcillo Carvajal; Anita María Murillo Zavala; María Isabel Peñaherrera Ortiz; Irma Gisella Parrales Pincay

Las infecciones agudas del tracto gastrointestinal figuran entre las enfermedades infecciosas más frecuentes. Los cuadros gastrointestinales pueden presentarse en cualquier época del año, pero el riesgo de sufrir estas enfermedades se incrementa en la temporada de calor.

Se afirma, que la gastroenteritis por Salmonella puede surgir en pequeños brotes en la población general. De 60 a 80\% de todos los casos son esporádicos; sin embargo, en ocasiones se producen grandes brotes en hospitales, instituciones para niños, restaurantes y hogares de ancianos, por alimentos contaminados en su origen o durante su manipulación por una persona enferma o un portador, aunque pueden deberse también a la transmisión de una persona a otra.

Se puede resaltar, que se describirá la metodología utilizada, los materiales y tipos de búsquedas empleadas en la investigación, se desarrollará el tema de la bacteria salmonella como un síndrome gastrointestinal causante de la salmonelosis, vías de contagio, estudios realizados, sustento en autores, prevención, tratamientos y preguntas frecuentes antes de asistir a una consulta por esta afección.

\section{Materiales y métodos}

Los materiales de trabajo utilizados en la investigación para el logro del trabajo consisten en computadores personales con conexión a internet, contenidos científicos académicos variados.

Esta investigación se enfoca en la búsqueda y revisión sistemática de literatura científico académica seleccionada, que, por una parte, está disponible determinadas bases de datos, entre las que figuran: MedlinePlus, PubMed, Biblioteca Virtual de la Salud (BVS), SciELO, Dialnet y 


\section{Síndrome diarreico infeccioso causado por Salmonella spp}

Vol. 3, núm. 3., (2019)

Carlos Pedro Marcillo Carvajal; Anita María Murillo Zavala; María Isabel Peñaherrera Ortiz; Irma Gisella Parrales Pincay

ELSEVIER, Cochrane, entre otras; y mediante el uso del material físicamente disponible en la biblioteca universitaria como en otras particulares, por la otra.

Principalmente se realiza una búsqueda aleatoria y consecutiva en las mencionadas bases de datos, usando las expresiones "Salmonella", "Salmonelosis", "contagio de salmonela" y “enfermedades gastrointestinales”, lo que aproximadamente resultó en más de un centenar de miles de registros bibliográficos. Luego éstos se filtran en base a criterios de: idioma español, relevancia, correlación temática y fecha de publicación en los últimos siete años, sin descartar por tipo de material bibliográfico; es decir, se escogen títulos de artículos científicos, ensayos, revisiones sistemáticas, protocolos, libros, boletines folletos de fuentes formales u oficiales, tesis posgrado y doctorado, noticias científicas, entre otros documentos e información de interés científico y académico. Se desestimaron estudios de cohorte, casos y controles; series y reportes de casos; artículos de revisión narrativa; editoriales, y cartas al editor.

Seguidamente, se efectúa la selección y clasificación de la literatura científica académica físicamente disponible, aplicando, en términos generales, los criterios antes mencionados, siendo a partir de allí que el equipo investigador le da la correspondiente lectura crítica y análisis de toda esa evidencia científica, lo que resultó consecutiva y consensuadamente en el fundamento de las ideas y planteamientos aquí plasmados. Estos procesos, en definitiva, representan parte esencial del proceso investigativo y de comprensión, que facilita la síntesis de la mejor evidencia disponible, y a su vez satisface uno de los resultados esperados. 


\section{Síndrome diarreico infeccioso causado por Salmonella spp}

Vol. 3, núm. 3., (2019)

Carlos Pedro Marcillo Carvajal; Anita María Murillo Zavala; María Isabel Peñaherrera Ortiz; Irma Gisella Parrales Pincay

\section{Resultados.}

"La salmonelosis es una enfermedad que puede producir náuseas, vómitos y diarrea. "Salmonella" es una bacteria. La infección se contrae de los alimentos ingeridos que la contienen". (Fundación española del aparato digestivo, 2019). Por tanto, es una infección común, de escasa gravedad en la mayoría de los afectados.

(Velasco J, 2019) Expresa: "Salmonella enterica se encuentra asociada a infecciones gastrointestinales y septicemia en el hospedero humano, gracias a su capacidad de invasión celular y sobrevivencia intrafagocítica".

Cabe destacar, que en ocasiones la bacteria llega a la sangre, si esto ocurre, determinados pacientes pueden sufrir una afectación mayor como lo son: sida, una enfermedad que altera el sistema de defensa del organismo, llamado sistema inmune, y lo debilita, también pacientes con cáncer: que han recibido quimioterapia recientemente tienen un mayor riesgo de enfermedad grave. Trasplantados (corazón, pulmón, riñones, entre otros). Drepanocitosis. Enfermedad que afecta a los glóbulos rojos de la sangre. Personas que toman dosis altas de corticoides u otros fármacos depresores del sistema inmune. Niños prematuros, menores de 3 años o con problemas inmunológicos.

La (Biblioteca Nacional de Medicina de los Estados Unidos, 2018) sostiene que "La Enterocolitis por salmonela es una infección bacteriana en el revestimiento del intestino delgado causada por la bacteria salmonela. Es un tipo de intoxicación por alimentos." Es así, que la infección por salmonela es uno de los tipos más comunes de intoxicación alimentaria. Esto 


\section{Síndrome diarreico infeccioso causado por Salmonella spp}

Vol. 3, núm. 3., (2019)

Carlos Pedro Marcillo Carvajal; Anita María Murillo Zavala; María Isabel Peñaherrera Ortiz; Irma Gisella Parrales Pincay

ocurre cuando se consumen alimentos o agua que contienen la bacteria salmonela. Los microorganismos de la salmonela pueden penetrar en el alimento que usted come de varias maneras.

Según el Centro de Prevención y Control de Enfermedades de los Estados Unidos de América (CDC, por sus siglas en inglés) (2019), estiman que la Salmonella causa alrededor de 1.2 millones de enfermedades, 23.000 hospitalizaciones y 450 muertes cada año en los Estados Unidos. Afirman que comida es la fuente de aproximadamente 1 millón de estas enfermedades. La mayoría de las personas infectadas con Salmonella desarrollan diarrea, fiebre y calambres abdominales de 6 horas a 4 días después de la infección. La enfermedad generalmente dura de 4 a 7 días y la mayoría de las personas se recuperan sin tratamiento. En algunas personas, la enfermedad puede ser tan grave que el paciente necesita ser hospitalizado.

La salmonelosis es una de las infecciones más importantes que afecta al humano y a los animales. Salmonella difícilmente se transfiere de persona a persona por lo que se considera que los alimentos son la principal y más probable fuente de exposición humana. Se han identificado más de 2000 serotipos de Salmonella que pueden causar salmonelosis en los humanos; no obstante, Salmonella Tiphymurium y Enteritidis sonmlos dos serotipos que principalmente se asocian con la enfermedad. (Puig, 2011)

Se afirma, que la gastroenteritis por Salmonella puede surgir en pequeños brotes en la población general. De 60 a $80 \%$ de todos los casos son esporádicos; sin embargo, en ocasiones se producen grandes brotes en hospitales, instituciones para niños, restaurantes y hogares de ancianos, por alimentos contaminados en su origen o durante su manipulación por una persona 


\section{Síndrome diarreico infeccioso causado por Salmonella spp}

Vol. 3, núm. 3., (2019)

Carlos Pedro Marcillo Carvajal; Anita María Murillo Zavala; María Isabel Peñaherrera Ortiz; Irma Gisella Parrales Pincay

enferma o un portador, aunque pueden deberse también a la transmisión de una persona a otra. La mayoría de las infecciones se deben a la ingestión de agua o productos alimentarios contaminados o debido al contagio fecal-oral. La incidencia máxima se observa en niños pequeños infectados durante los meses cálidos del año, al consumir alimentos contaminados como ensaladas con huevos durante reuniones sociales.

Cabrera (2013) expresa:

La diarrea puede durar varios días y puede privar al organismo del agua y las sales necesarias para la supervivencia. La mayoría de las personas que fallecen por enfermedades diarreicas, de hecho, mueren por una grave deshidratación y pérdida de líquidos. Se trata de una patología de relevante importancia sanitaria, cuyo manejo es relativamente fácil por parte de personal capacitado, pero que requiere para su control de una provisión de agua potable, condiciones higiénicas, alimentarias, y adecuado control de las excretas, ya que su propagación se realiza por vía fecal- oral. (pp. 118)

Es así, que la infección se transmite por alimentos o agua de consumo contaminado, o bien, de una persona a otra como resultado de una higiene deficiente. En los países en desarrollo, los niños menores de tres años sufren en promedio tres episodios de diarrea al año. Cada episodio priva al niño de nutrientes necesarios para su crecimiento. En consecuencia, la diarrea es una importante causa de malnutrición, y los niños malnutridos son más propensos a enfermarse. 


\section{Síndrome diarreico infeccioso causado por Salmonella spp}

Vol. 3, núm. 3., (2019)

Carlos Pedro Marcillo Carvajal; Anita María Murillo Zavala; María Isabel Peñaherrera Ortiz; Irma Gisella Parrales Pincay

Por otro lado, Quesada (2016) indica que:

[...] los resultados de Salmonella spp aislados en los estudios incluidos mostraron, con frecuencia, resistencia a antibióticos que son usados como primera opción en el tratamiento de salmonelosis en humanos, como cloranfenicol, ciprofloxacina, trimetoprim-sulfametoxazol y ceftriaxona. De acuerdo con los resultados, los aislamientos de Salmonella spp presentaron resistencia a cefotaxima con menor frecuencia que a otros antibióticos de uso frecuente en la salmonelosis, por lo que este antibiótico podría resultar la mejor opción terapéutica para iniciar un tratamiento empírico. Sin embargo, estos resultados deben ser confirmados en un mayor número de estudios.

Afirma el Departamento de Agricultura de los Estados Unidos de Amárica (USDA) (2013) que las bacterias "Salmonella" son la causa de enfermedades transmitidas por alimentos frecuentemente reportadas. Un enfoque completo sobre la inocuidad alimentaria, desde la granja hasta la mesa, es necesario para reducir la salmonellosis. Los granjeros, la industria, los inspectores de alimentos, los vendedores de alimentos, los trabajadores en el servicio de alimentos y los consumidores son cada uno un eslabón importante en la cadena de la inocuidad de alimentos. Este documento contesta preguntas comunes sobre la bacteria Salmonella, describe cómo el Servicio de Inocuidad e Inspección de los Alimentos (FSIS, por sus siglas en inglés) del Departamento de Agricultura de los Estados Unidos (USDA, por sus siglas en inglés) está atendiendo el problema de la contaminación de productos de carnes y aves con Salmonella y ofrece pautas para un manejo de alimentos que prevenga bacterias, como Salmonella causen enfermedades. 


\section{Síndrome diarreico infeccioso causado por Salmonella spp}

Vol. 3, núm. 3., (2019)

Carlos Pedro Marcillo Carvajal; Anita María Murillo Zavala; María Isabel Peñaherrera Ortiz; Irma Gisella Parrales Pincay

La Organización Mundial de la Salud (2019), sostiene que la salmonelosis, causada por la bacteria Salmonella, es una de las enfermedades de transmisiones alimentarias más comunes y ampliamente extendidas. Se estima que afecta anualmente a decenas de millones de personas de todo el mundo y provoca más de cien mil defunciones. Los síntomas de la enfermedad comienzan a manifestarse entre 6 y 72 horas (generalmente 12 a 36 horas) después de la ingesta de Salmonella, y la enfermedad dura entre 2 y 7 días. En la mayoría de los casos, los síntomas de salmonelosis son relativamente leves y los pacientes se recuperan sin tratamiento específico. Sin embargo, en algunos casos, particularmente en niños pequeños y en ancianos, la deshidratación causada por la enfermedad puede ser grave y poner en peligro la vida.

\section{Prevención}

Se puede disminuir las probabilidades de contraer o contagiar la infección a otras personas mediante: lavado de manos tras cambiar pañales, ir al baño, sonarse la nariz, tocar animales o sacar la basura. Quedarse en casa (sin asistir al colegio o al trabajo) si usted está enfermo. Prestar atención a los alimentos que se ingieren: No beber leche sin pasteurizar o comer alimentos hechos en ella. Lavar frutas y verduras bien antes de comerlas. Mantener la temperatura del frigorífico por debajo de $4.4^{\circ} \mathrm{C}$ y el congelador por debajo de $-18^{\circ} \mathrm{C}$. Cocinar bien carnes y pescados. Cocinar los huevos hasta que la yema esté cuajada. Lavar manos, cuchillos y demás utensilios de cocina tras el contacto con alimentos crudos. 


\section{Síndrome diarreico infeccioso causado por Salmonella spp}

Vol. 3, núm. 3., (2019)

Carlos Pedro Marcillo Carvajal; Anita María Murillo Zavala; María Isabel Peñaherrera Ortiz; Irma Gisella Parrales Pincay

\section{Tratamiento y Medicamentos}

Mayo Clinic (2019) sostiene y recomienda para la infección por salmonella, debido a que ésta causa deshidratación, el tratamiento se centra en el reemplazo de líquidos y de electrólitos. Los casos graves pueden requerir hospitalización y administración de líquidos directamente en una vena (intravenosa). Además, tu médico puede recomendarte lo siguiente:

- Antidiarreicos. Los medicamentos como la loperamida (Imodium A-D) pueden ayudar a aliviar los cólicos, aunque también podrían prolongar la diarrea asociada con la infección por salmonela.

- Antibióticos. Si tu médico sospecha que la bacteria salmonela ingresó a tu torrente sanguíneo, o si tienes un caso grave o estás inmunodeprimido, este puede recetarte antibióticos para matar la bacteria. Los antibióticos no son convenientes en casos que no sean graves. De hecho, los antibióticos pueden prolongar el período durante el cual eres portador de la bacteria y puedes infectar a otros; además, pueden aumentar el riesgo de recaídas.

Si no se necesita atención médica para la infección por salmonela, se debe tener cuidado de no deshidratarte, una preocupación frecuente junto con la diarrea y los vómitos.

Los adultos deberían beber agua o chupar trozos de hielo. En el caso de los niños, puedes utilizar una solución de rehidratación oral, a menos que el especialista indique lo contrario. 


\section{Síndrome diarreico infeccioso causado por Salmonella spp}

Vol. 3, núm. 3., (2019)

Carlos Pedro Marcillo Carvajal; Anita María Murillo Zavala; María Isabel Peñaherrera Ortiz; Irma Gisella Parrales Pincay

Antes de realizar una consulta se debe seguir ciertas indicaciones y prepararse, la mayoría de las personas no necesitan buscar atención médica para la infección por salmonela porque desaparece por sí sola en unos días. Sin embargo, en los casos que afectan a bebés, niños pequeños, adultos mayores y personas con el sistema inmunitario debilitado, se debe llamar al médico si la enfermedad dura más de unos pocos días, si hay fiebre alta o heces con sangre, o si parece provocar deshidratación.

Otras sugerencias antes de realizar una consulta, es preguntar si hay algo que hacer con anticipación, como restringir la dieta, anotar los síntomas, incluso los que parezcan no tener relación con el motivo por el que necesite la consulta. Anote su información personal más importante, como lo que le cause más estrés o cualquier cambio reciente en su vida o viaje reciente. Haga una lista de todos los medicamentos, las vitaminas y los suplementos que estés tomando. Pídale a un familiar o a un amigo que lo acompañe, si es posible. La persona que le acompañe puede recordar información que haya pasado por alto u olvidado. Anote las preguntas que desees hacerle al médico. Preparar una lista de preguntas para hacerle al médico le ayudará a aprovechar al máximo el tiempo de la consulta.

Para la infección por salmonela, algunas preguntas básicas que puede realizarle al médico son las siguientes: ¿Qué podría estar provocando los síntomas o la enfermedad? Además de la causa más probable, ¿cuáles son otras posibles causas de los síntomas o de la enfermedad? ¿Qué pruebas necesito hacer? ¿Cuáles serían las mejores medidas para tomar? ¿Cuáles son las alternativas al enfoque principal que sugieres? Que otros problemas de salud se padece. ¿Cuál es la mejor manera de controlarlos en forma conjunta? ¿Se debe respetar alguna restricción? 


\section{Síndrome diarreico infeccioso causado por Salmonella spp}

Vol. 3, núm. 3., (2019)

Carlos Pedro Marcillo Carvajal; Anita María Murillo Zavala; María Isabel Peñaherrera Ortiz; Irma Gisella Parrales Pincay

¿Debería consultar a un especialista? ¿Existe alguna alternativa genérica al medicamento que se receta?

Por otro lado, el médico también necesitará saber: cuándo comenzó la enfermedad, la frecuencia de los vómitos o diarrea, si los vómitos o las heces contienen bilis, mucosidad o sangre visibles, si tienes fiebre, si viajaste recientemente al extranjero.

\section{Conclusiones.}

La salmonelosis es una enfermedad que sigue teniendo una condición presente en diferentes partes del mundo, muy frecuente en países en vías de desarrollo, y por este motivo debe velarse por una mejor política sanitaria en aquellos sitios donde las infecciones aún presentan una alta prevalencia.

Se puede hacer notar, que la transmisión y desarrollo de infecciones relacionadas a Salmonella son de especial cuidado. Cabe resaltar el hecho de que el uso continuo de antibióticos ha generado la aparición de cepas resistentes en varios lugares en el mundo, tal y como ha ocurrido con otras bacterias, lo que genera una necesidad creciente por un mayor apego a los protocolos de manejo y a su vez una correcta educación en el uso de los antibacterianos para los pacientes a quienes se les suministra estas terapias.

Por otro lado, existen riesgos derivados de la presencia de Salmonella spp. en huevos y pollos para asar, en alimentos listos para el consumo, en vegetales, en lugares donde críen aves y mascotas tipo reptiles, la consulta de expertos llegó a la conclusión de que, en conjunto, el proyecto de las evaluaciones de riesgos era amplio y de gran calidad. El trabajo representó un 


\section{Síndrome diarreico infeccioso causado por Salmonella spp}

Vol. 3, núm. 3., (2019)

Carlos Pedro Marcillo Carvajal; Anita María Murillo Zavala; María Isabel Peñaherrera Ortiz; Irma Gisella Parrales Pincay

avance considerable en la aplicación del conocimiento científico que permite mejorar la base objetiva para gestionar los peligros microbiológicos en la cadena alimentaria.

También, la consulta a fuentes bibliográficas permitió conocer la aplicabilidad y la utilidad de dichas fuentes disponibles, la necesidad de datos basados en encuestas y estudios experimentales diseñados específicamente para proporcionar información para evaluaciones de riesgos microbiológicos.

Se tuvo la oportunidad de realizar un análisis de la importancia de la prevención de riesgos sobre la propagación de la enfermedad y posibles tratamientos.

Asimismo, la consulta concluyó que la organización mundial de la salud coloca a salmonelosis como una afección a tomar en cuenta para emprender la evaluación de riesgos microbiológicos que podría mejorarse, e identificó algunas de las materias principales que han de abordarse.

\section{Referencias Bibliográficas}

Biblioteca Nacional de Medicina de los Estados Unidos. (24 de Febrero de 2018). Medline Plus, 1. (M. Plus, Editor, B. N. Unidos, Productor, \& Biblioteca Nacional de Medicina de los Estados Unidos) Recuperado el 17 de Septiembre de 2019, de Medline Plus: https://medlineplus.gov/spanish/ency/article/000294.htm

Cabrera, D. M. (1 de septiembre de 2013). Enfermedad diarreica aguda en niños menores de cinco años de edad: aportaciones de los núcleos trazadores de vigilancia epidemiológica 20122013. (I. m. social, Ed.) Investigación materno infantil, 5(3), 118-125. Recuperado el 17 de septiembre de 2019, de http://www.medigraphic.org.mx/

Centro de prevención y control de enfermedades. (2019). Salmonella. Centers for disease Control and Prevention, U.S. Department of Health \& Human Services. Druid Hills: U.S. 


\section{Síndrome diarreico infeccioso causado por Salmonella spp}

Vol. 3, núm. 3., (2019)

Carlos Pedro Marcillo Carvajal; Anita María Murillo Zavala; María Isabel Peñaherrera Ortiz; Irma Gisella Parrales Pincay

Department of Health \& Human Services. Retrieved Septiembre 17, 2019, from https://www.cdc.gov/salmonella/

Fundación española del aparato digestivo. (01 de Julio de 2019). Salmonelosis, 1. (F. e. digestivo, Editor, F. e. digestivo, Productor, \& Fundación española del aparato digestivo) Recuperado el 2019 de Septiembre de 17, de Fundación española del aparato digestivo: https://www.saludigestivo.es/mes-saludigestivo/toxiinfecciones-alimentarias/salmonelosis/

Hernández C, A. M. (octubre de 2011). Situación de las enfermedades gastrointestinales en México. (Elsevier, Ed.) Enfermedades infecciosas y microbiología, 31(4), 38. Recuperado el 17 de septiembre de 2019, de https://www.medigraphic.com/pdfs/micro/ei-2011/ei114f.pdf

Mayo Clinic. (17 de septiembre de 2019). Boletin de salud de Mayo Clinic, 1. (M. Clinic, Editor, M. f. research, Productor, \& Mayo Clinic) Recuperado el 17 de septiembre de 2019, de Mayo Clinic: https://www.mayoclinic.org/es-es/diseases-conditions/salmonella/symptoms-causes/syc20355329

Organización Mundial de la Salud. (17 de septiembre de 2019). Temas de salud, salmonelosis. Obtenido de Organización Mundial de la Salud: https://www.who.int/topics/salmonella/es/

Puig, Y. (1 de abril de 2011). Resistencia antimicrobiana en Samonella y E. coli aisladas en alimentos: revisión de literatura. (P. C. Salud, Ed.) Panorama Cuba y Salud, 6(1), 30-38. $\begin{array}{lllllll}\text { Recuperado el } & \text { el } & \text { de } & \text { septiembre }\end{array}$ http://revpanorama.sld.cu/index.php/panorama/article/view/74/pdf

Quesada, A. e. (09 de 03 de 2016). Resistencia antimicrobiana de Salmonella spp aislada de alimentos de origen animal para consumo humano. (R. p. Pública, Ed.) Revista peruana de medicina experiemental de salud pública, 36. doi:http://doi.org/10.17843/rpmesp.2016.331.1899

USDA. (20 de noviembre de 2013). United States Department of Agriculture, 1. (U. S. Agriculture, Editor, U. S. Agriculture, Productor, \& United States Department of Agriculture) Recuperado el 17 de septiembre de 2019, de fsis.usda.gov: http://www.fsis.usda.gov/wsp/portal/infomational/en-espanol/hojasinformativas/enfermedadespor-alimentos/salmonella-preguntas-y-respuestas/salmonella-preguntas-y-respuestas

Velasco J, e. a. (2019). Patogenia de mutantes de Salmonella Typhimurium en dos modelos. (F. ediciones, Ed.) Vacci monitor, 28(1), 1-8. Recuperado el 17 de Septiembre de 2019, de https://www.medigraphic.com/pdfs/vaccimonitor/vcm-2019/vcm191a.pdf 